\title{
Investigation of bio-based polyamide with short fibers for lightweight structures
}

\author{
Roman Rinberg ${ }^{1)}$, Tobias Hartmann²), Anton Nikiforov ${ }^{3)}$, Anton Doynikov4), Svetoslav Volfson ${ }^{5}$, Lothar
} Kroll ${ }^{6)}$

1)Department of Lightweight Structures and Polymer Technology, roman.rinberg@mb.tuchemnitz.de, Chemnitz University of Technology, Reichenhainer Str. 31/33, 09126 Chemnitz, Germany

2) Department of Lightweight Structures and Polymer Technology, tobias.hartmann@mb.tuchemnitz.de, Chemnitz University of Technology, Reichenhainer Str. 31/33, 09126 Chemnitz, Germany

3) Department of Chemistry and Technology of Elastomer Processing, antonnikifor@gmail.com, Kazan National Research Technological University, Karl Marx Str. 72, 420015 Kazan, Russian Federation

4) Department of Chemistry and Technology of Elastomer Processing, doynikovantoniy@gmail.com, Kazan National Research Technological University, Karl Marx Str. 72, 420015 Kazan, Russian Federation

5) Department of Chemistry and Technology of Elastomer Processing, svolfson@kstu.ru, Kazan National Research Technological University, Karl Marx Str. 72, 420015 Kazan, Russian Federation

6) Department of Lightweight Structures and Polymer Technology, slk@mb.tu-chemnitz.de, Chemnitz University of Technology, Reichenhainer Str. 31/33, 09126 Chemnitz, Germany

\section{Keywords}

Bio-based polyamide, biopolyamide, fiber length distribution, lightweight structure, short carbon fibers, short glass fibers, twin screw extruder

\begin{abstract}
In the automotive industry, petrochemical plastics are widespread because glass and carbon fiberreinforced composites consist exclusively of petroleum-based matrix materials. So far, bio-based plastics couldn't meet the requirement profile due to their high prices, their inappropriate features and the ineligible quality assurance of their synthesis. But the development of new bio-based polyamides opens the opportunity to replace petroleum-based plastics and may initiate the use of bio-based plastic matrices for fiber-reinforced composites for automotive applications.

In this study, short fiber-reinforced polyamide 10.10 composites were investigated. Short carbon and glass fibers were used in varying compositions along with different modifiers to optimize the resulting characteristics. Fiber breakage during twin screw extrusion processing was researched and affected by the use of lubricants. The effect of using lubricants was noticed after extrusion. The addition of lubricants caused negative effects on mechanical properties at concentrations higher than $0.5 \%$ wt. Further influences on fiber matrix interactions were investigated by varying the parameters of injection molding and positive effects on tensile properties were recognized. Strengthening effects on resulting composites are discussed in terms of lightweight structure and cost-efficiency.
\end{abstract}

\section{Introduction}

The total production of bio-based plastics was 4.2 million tons in 2016 and is predicted to rise up to 6.1 million tons in 2021 by experts of the field. Biopolyamides had a share of $3.5 \%$ in 2016 and could grow

Digital Object Identifier: http://dx.doi.org/10.21935/tls.v1i2.89 www.lightweight-structures.de

This is an open access article under the CC BY license (http://creativecommons.org/licenses/BY/4.0/) 
rapidly depending on new application areas [1]. Especially the automotive industry has a high potential to become one of those since the use of high strength and temperature stable petrochemical derived polyamides is widespread in both exterior and interior parts to deal with aggressive fluids and high temperatures (e.g. air filtration units, restrictor valves and other valves in engine parts) [2, 3]. Apart from that, fiber-reinforced bio-polyamides could also match the profile for "under the hood" use. The high heat deflection required for this is achieved by carbon or glass fiber-reinforcement. The reinforcing fibers contribute to a much higher stiffness and tensile strength to the mechanical properties of the composite than the matrix. Therefore, fibers take load from the matrix during deformation, and the composite can withstand higher loads due to this fact. The transfer of load from the matrix to the fiber is carried out by shear stress of the fiber-matrix interface and depends on the fiber-matrix adhesion and the fiber length. The longer the chopped fiber in the composite the more load it can bear. Production of those short fiberreinforced composites for injection molding is state of the art via twin screw extrusion. The length of the fibers changes during processing due to fiber breakage. The processing conditions have been investigated by Thomason et al. who established that a higher content of fibers leads to more intensive fiber breakage $[4,5]$. However, the occurrence of increased viscosity and fiber breakage during processing with high fiber contents is still a topic of research. In this context, the transfer of load from matrix to fibers is the critical focus. In cases where fibers haven't reached the critical fiber length because of breakage, the polymer matrix is unable to transfer more load [6]. Thus, fiber breakage has a high influence on mechanical properties and it is important to investigate the fiber length distribution in obtained composites to estimate the intensity of fiber breakage. Therefore, a determination of the fiber length distribution after extrusion and after injection molding is necessary. As a result, the impact on the contribution of fiber length could be identified and analyzed.

In the area of polyamide 10.10 composites, the investigation of fiber reinforcement is a current topic of research. Feldmann et al. already noticed that the mechanical properties in composites based on polyamide 10.10 with cellulose fibers have mechanical properties comparable to properties of glass reinforced composites, except for the young's modulus [7-9]. Kuciel et al. investigated composites of two types of polyamide 10.10 with carbon fibers and observed an increasing of tensile strength to nearly $185 \mathrm{MPa}$ for polyamide 10.10 with $40 \%$ wt. carbon fibers and an elastic modulus to more than $23 \mathrm{GPa}$ $[10,11]$. In our previous research, some fiber-reinforced polyamide 10.10 composites with lubricants were investigated. The results show the effect of decreasing mechanical properties, possibly due to decreasing interfacial interaction between matrix and fibers because of the lubricants used. Also, we have observed the decreasing of tensile strength of composites with $40 \%$ wt. of carbon fibers in comparison with $30 \%$ wt. [12-15].

The effects of changing properties of fiber-reinforced composites with revised processing temperature were observed previously by Lafranche and Mathurosemontri [16, 17]. Increasing the processing temperature has led to enhanced flexural properties with polyamide. In research on polyoxymethylene, the realization of the tensile strength of the composite which was processed at high temperatures was $12 \%$ higher compared to a lower temperature. Hence, it is promising to study tensile properties at different processing temperatures in injection molding.

This study shows an attempt to lower viscosity and shear stress by using lubricants to reduce the intensity of fiber breakage due to the decreased viscosity during extrusion. The second attempt entails varying processing conditions during injection molding. The effect of the process temperature is studied in this paper.

\section{Materials and methods}

\subsection{Materials}

The polymer matrix is $100 \%$ bio-based polyamide 10.10 VESTAMID TERRA DS16 (PA 10.10) with a density of $1050 \mathrm{~kg} / \mathrm{m}^{3}$ produced by Evonik industries.

The reinforcer is glass fiber CS7928 (GF) with an average length of $4.5 \mathrm{~mm}$, a diameter of $11 \mu \mathrm{m}$, a tensile modulus of $70 \mathrm{GPa}$ and a tensile strength of $3.5 \mathrm{GPa}$ from Lanxess AG. Another reinforcer is carbon fiber Sigrafil C30 S003PUT (CF) with an average length of $3 \mathrm{~mm}$, a diameter of $7 \mu \mathrm{m}$, a tensile modulus of $240 \mathrm{GPa}$ and a tensile strength of $4 \mathrm{GPa}$, produced by SGL carbon SE. 
The investigated lubricants are two types of montan waxes delivered by Clariant. The official trade names are Licowax E (LE) powder, an ester of montanic acid with multifunctional alcohols, and Licowax OP (LOP), a partly saponified ester wax of montanic acid.

\subsection{Composite preparation}

In a first step, PA 10.10 was dried for 4 hours at $80{ }^{\circ} \mathrm{C}$ to $0.1 \%$ of residual moisture. The dried components were compounded on a Noris Plastic ZSC 25/44D twin screw extruder with screw diameters of $25 \mathrm{~mm}$ and a length-diameter ratio of 44 at a processing temperature ranging from $190-240{ }^{\circ} \mathrm{C}$ and a screw speed of 200-300 rpm equipped with a gravimetric feeder.

Injection molded test specimens were performed on an Arburg All Drive 370 according to ISO 527, at a temperature of $220-250^{\circ} \mathrm{C}$ and a mold temperature of $60^{\circ} \mathrm{C}$. In the course of the optimization of the injection molding process, the temperature was extended to $350^{\circ} \mathrm{C}$. The granules were dried before processing for 4 hours at $80^{\circ} \mathrm{C}$.

The composition of the obtained composites is shown in Table 1. Because a reinforcing effect of fibers in composites is connected to volume, content composites are labeled according to the type of fibers and their volume content. To complete the picture, the mass content of the reinforcer is also noted in the table. The influence of lubricants on the reinforcing fiber breakage was shown on composites with a $20 \%$ vol. of glass fibers.

Table 1: Composition of composites of PA 10.10 with fiber reinforcement

\begin{tabular}{|c|c|c|c|c|c|}
\hline \multirow{2}{*}{$\begin{array}{l}\text { Composites of } \\
\text { PA } 10.10\end{array}$} & \multirow[t]{2}{*}{ Type of fiber } & \multicolumn{2}{|c|}{ Fiber content } & \multirow{2}{*}{$\begin{array}{c}\text { Type of } \\
\text { lubricant }\end{array}$} & \multirow{2}{*}{$\begin{array}{r}\text { Lubrican } \\
\text { content } \\
\text { [\% wt.] }\end{array}$} \\
\hline & & [\% vol.] & [\% wt.] & & \\
\hline GF-6 & glass & 6 & 13.5 & - & - \\
\hline GF-13 & glass & 13 & 27.8 & - & - \\
\hline GF-20 & glass & 20 & 40 & - & - \\
\hline GF-20-LE-0.5 & glass & 20 & 40 & Licowax E & 0.5 \\
\hline GF-20-LE-1.0 & glass & 20 & 40 & Licowax E & 1.0 \\
\hline GF-20-LE-2.0 & glass & 20 & 40 & Licowax E & 2.0 \\
\hline GF-20-LOP-0.5 & glass & 20 & 40 & Licowax OP & 0.5 \\
\hline GF-20-LOP-1.0 & glass & 20 & 40 & Licowax OP & 1.0 \\
\hline GF-20-LOP-2.0 & glass & 20 & 40 & Licowax OP & 2.0 \\
\hline CF-6 & carbon & 6 & 10 & - & - \\
\hline $\mathrm{CF}-13$ & carbon & 13 & 20 & - & - \\
\hline CF-20 & carbon & 20 & 30 & - & - \\
\hline
\end{tabular}

During the processing of the composites, fibers significantly change their length due to fiber breakage. Therefore, the fiber length distribution after extrusion and after injection molding was measured.

The fiber length of the composites was determined after both processing steps, by incineration of the polymer matrix in a muffle kiln at $500^{\circ} \mathrm{C}$ under nitrogen. The remaining fibers were placed in a high definition scanner FASEP 3E Eco System from XYZ HIGH PRECISION for analyzing images. For a better statistical reliability, a minimum of 10 thousand fibers for each sample were measured.

\subsection{Methods}

Material testing was performed according to ISO: 
- tensile test (ISO 527, load cell $10 \mathrm{kN}$, testing speed for tensile modulus was $1 \mathrm{~mm} / \mathrm{min}$ and testing speed for tensile strength was $5 \mathrm{~mm} / \mathrm{min}$ )

- flexural test (ISO 178, load cell with $1 \mathrm{kN}$ and testing speed of $5 \mathrm{~mm} / \mathrm{min}$ )

- Charpy impact test (ISO 179, pendulum of $2 \mathrm{~J}$ )

- determination of deflection temperatures under load (ISO 75)

- density measurement (ISO 1183).

All tests were performed at room temperature unless otherwise specified.

\section{Results}

The different degrees of glass and carbon fiber breakage during extrusion and injection molding were connected to the different fiber transverse and longitudinal properties: strength of carbon and glass along the fiber are comparable, but the transverse strength of glass fibers is much higher than that of carbon fibers. Because the diameter of carbon fibers is smaller compared to that of glass fibers, it could be assumed that the same level of load during the extrusion breaks carbon fibers more intensively. And indeed this behavior has been observed during extrusion. In a similar way, fiber breakage during injection molding, where shear stress on fibers is much higher than during extrusion, could also be explained.

For a better understanding and interpretation of the correlations between fiber length, mechanical properties, and processing procedures, the fibers with length $(\mathrm{L})$ were divided into three groups: fibers with less than critical length $\left(L_{c r}\right)$, fibers with $L$ between 1 and $2 L_{c r}$, and fibers with $L$ longer than $2 L_{c r}$. The critical fiber length $L_{c r}$ was calculated according to equation (1) [18] at an ideal matrix-fiber interfacial adhesion. For glass fiber-reinforced composites it equals $458 \mu \mathrm{m}$ and for carbon fiber-reinforced composites $333 \mu \mathrm{m}$.

$$
\frac{L_{c r}}{D_{f}}=\frac{\sigma_{f}}{2 \tau_{m a t}}
$$

with $L_{c r}-$ critical fiber length; $D_{f}-$ fiber diameter; $\sigma_{f}-$ tensile strength of fibers; $\tau_{m a t}$ - tensile yield stress of polymer matrix.

In Table 2, the increasing amount of fibers, which are shorter than the critical length after injection molding is shown in comparison to extrusion processing. It is important to mention that there are less fibers with a length that is shorter than the critical fiber length in glass fiber-reinforced composites. Hence, the glass fibers better withstand processing and thus contribute more to the mechanical properties. Composites with $13 \%$ vol. and $20 \%$ vol. glass fibers seem to have similar fiber length distributions after extrusion but not after injection molding.

Table 2: Fiber length distributions of composites after extrusion and after injection molding

\begin{tabular}{|c|c|c|c|c|c|c|}
\hline \multirow[t]{2}{*}{$\begin{array}{l}\text { Composites } \\
\text { of PA } 10.10\end{array}$} & \multicolumn{2}{|c|}{$\begin{array}{l}\text { Fiber length distribution } \\
\text { after extrusion }\end{array}$} & \multirow[b]{2}{*}{$\begin{array}{c}2 \mathrm{~L}_{c r}<\mathrm{L} \\
{[\%]}\end{array}$} & \multicolumn{2}{|c|}{$\begin{array}{l}\text { Fiber length distribution } \\
\text { after injection molding }\end{array}$} & \multirow[b]{2}{*}{$\begin{array}{c}2 \mathrm{~L}_{\mathrm{cr}}<\mathrm{L} \\
{[\%]}\end{array}$} \\
\hline & $\begin{array}{c}\mathrm{L}<\mathrm{Lcr}^{*}{ }^{*} \\
{[\%]}\end{array}$ & $\begin{array}{c}\mathrm{L}_{c r}<\mathrm{L}<2 \mathrm{~L}_{\mathrm{cr}} \\
{[\%]}\end{array}$ & & $\begin{array}{c}\mathrm{L}<\mathrm{L}_{c r} \\
{[\%]}\end{array}$ & $\begin{array}{c}\mathrm{L}_{c r}<\mathrm{L}<2 \mathrm{~L}_{\mathrm{cr}} \\
{[\%]}\end{array}$ & \\
\hline GF-6 & 56.8 & 39.7 & 3.4 & 67.4 & 30.7 & 1.9 \\
\hline GF-13 & 78.9 & 19.9 & 1.2 & 77.2 & 20.6 & 2.2 \\
\hline GF-20 & 79.0 & 19.4 & 1.6 & 85.5 & 14.1 & 0.4 \\
\hline CF-6 & 82.4 & 15.3 & 2.4 & 90.1 & 8.6 & 1.3 \\
\hline CF-13 & 82.5 & 15.6 & 1.9 & 91.3 & 7.5 & 1.2 \\
\hline CF-20 & 90.0 & 8.8 & 1.2 & 93.6 & 6.0 & 0.4 \\
\hline
\end{tabular}

${ }^{*}$ measured fiber length $L$ and calculated critical fiber length $L$ cr 
A similarly strong effect of processing on the average fiber length was reported by Thomason [4]. For PA66 with glass fiber contents of $5 \%$ vol. to over $20 \%$ vol. the average length is reduced by more than $50 \%$. The same applies when processing PA6 with glass fibers on an industrial twin screw extruder, Inceoglu et al. [5] found a strong reduction in the average fiber length to approx. 300-350 $\mu \mathrm{m}$ from 200 rpm.Table 2 also points out that viscosity has different effects on the fiber length during extrusion and injection molding processes. It is shown that carbon fiber-reinforced composites have different fiber length distributions after extrusion. After injection molding it becomes the same for all samples, independently of the fiber volume content.

Adding lubricants to glass-reinforced composites should influence the fiber breakage. To investigate the influence of added lubricants on fiber breakage, fiber length distributions are summarized in Table 3. Adding $0.5 \%$ wt. of lubricants did not significantly affect the fiber length distribution after extrusion. However, adding $2 \%$ wt. of lubricants lowered the intensity of fiber breakage after extrusion. After the injection molding process, no significant effect of lubricants could be determined. The results of mechanical testing for neat PA 10.10 and its composites are shown in Table 4.

Table 3: Fiber length distribution in composites of PA 10.10 with $20 \%$ vol. GF and with lubricants after extrusion and after injection molding

\begin{tabular}{|c|c|c|c|c|c|c|}
\hline \multirow[t]{2}{*}{$\begin{array}{l}\text { Composites } \\
\text { of PA } 10.10\end{array}$} & \multicolumn{2}{|c|}{$\begin{array}{l}\text { Fiber length distribution } \\
\text { after extrusion }\end{array}$} & \multirow[b]{2}{*}{$\begin{array}{c}2 \mathrm{~L}_{c r}<\mathrm{L} \\
{[\%]}\end{array}$} & \multicolumn{2}{|c|}{$\begin{array}{l}\text { Fiber length distribution } \\
\text { after injection molding }\end{array}$} & \multirow[b]{2}{*}{$\begin{array}{c}2 \mathrm{~L}_{\mathrm{cr}}<\mathrm{L} \\
{[\%]}\end{array}$} \\
\hline & $\begin{array}{c}L<L_{c r} \\
{[\%]}\end{array}$ & $\begin{array}{c}\mathrm{L}_{c r}<\mathrm{L}<2 \mathrm{~L}_{\mathrm{cr}} \\
{[\%]}\end{array}$ & & $\begin{array}{c}\mathrm{L}<\mathrm{L}_{c r} \\
{[\%]}\end{array}$ & $\begin{array}{c}\mathrm{L}_{c r}<\mathrm{L}<2 \mathrm{~L}_{\mathrm{cr}} \\
{[\%]}\end{array}$ & \\
\hline GF-20-LE-0.5 & 80.7 & 18.4 & 0.8 & 87 & 12.2 & 0.8 \\
\hline GF-20-LE-1.0 & 80.5 & 17.9 & 1.6 & 81.3 & 17.9 & 0.8 \\
\hline GF-20-LE-2.0 & 67.6 & 26.6 & 5.8 & 86.3 & 13.1 & 0.7 \\
\hline GF-20-LOP-0.5 & 80.6 & 18.6 & 0.8 & 83.9 & 15.2 & 0.8 \\
\hline GF-20-LOP-1.0 & 80.4 & 18.7 & 0.9 & 81.0 & 18.2 & 0.8 \\
\hline GF-20-LOP-2.0 & 76.7 & 22.1 & 1.2 & 81.8 & 16.2 & 2.0 \\
\hline
\end{tabular}

Table 4: Density and mechanical properties of PA 10.10 and composites with glass or carbon fibers

\begin{tabular}{|c|c|c|c|c|c|c|c|}
\hline \multirow[t]{2}{*}{$\begin{array}{l}\text { Composites } \\
\text { of PA } 10.10\end{array}$} & Density & $\begin{array}{l}\text { Tensile } \\
\text { modulus }\end{array}$ & $\begin{array}{l}\text { Tensile } \\
\text { strength }\end{array}$ & $\begin{array}{l}\text { Flexural } \\
\text { modulus }\end{array}$ & $\begin{array}{l}\text { Flexural } \\
\text { strength }\end{array}$ & $\begin{array}{l}\text { Notched } \\
\text { Charpy } \\
\text { impact } \\
\text { strength }\end{array}$ & $\begin{array}{l}\text { Unnotched } \\
\text { Charpy } \\
\text { impact } \\
\text { strength }\end{array}$ \\
\hline & {$\left[\mathrm{kg} / \mathbf{m}^{3}\right]$} & [MPa] & [MPa] & [MPa] & [MPa] & {$\left[\mathrm{kJ} / \mathbf{m}^{2}\right]$} & {$\left[\mathbf{k J} / \mathbf{m}^{2}\right]$} \\
\hline Unfilled & 1,050 & $1,673 \pm 9.3$ & $45.9 \pm 2$ & $1,344 \pm 62$ & $58.9 \pm 1$ & $5.9 \pm 0.9$ & no break \\
\hline GF-6 & 1,140 & $4,026 \pm 23$ & $82.6 \pm 0.5$ & $3,060 \pm 57$ & $116.4 \pm 1$ & $5.6 \pm 1.2$ & $57.5 \pm 4.3$ \\
\hline GF-13 & 1,260 & $6,595 \pm 57$ & $110.8 \pm 1$ & $6,595 \pm 34$ & $170 \pm 1$ & $11.1 \pm 1.4$ & $66.4 \pm 4.3$ \\
\hline GF-20 & 1,370 & $9,295 \pm 70$ & $130.7 \pm 1$ & $7,840 \pm 76$ & $207.9 \pm 1$ & $12.8 \pm 0.5$ & $69.4 \pm 3.3$ \\
\hline CF-6 & 1,100 & $6,340 \pm 24$ & $86.2 \pm 0.3$ & $5,085 \pm 59$ & $125 \pm 1$ & $4.8 \pm 0.5$ & $42.5 \pm 0.9$ \\
\hline CF-13 & 1,140 & $10,151 \pm 343$ & $106.2 \pm 3$ & $8,776 \pm 137$ & $155.6 \pm 1.2$ & $6.2 \pm 0.1$ & $40.8 \pm 1.5$ \\
\hline CF-20 & 1,200 & $15,134 \pm 279$ & $127 \pm 0.8$ & $13,417 \pm 186$ & $188.9 \pm 2$ & $7.2 \pm 0.1$ & $45.3 \pm 1.4$ \\
\hline
\end{tabular}

Composites with the same volume of fibers have similar tensile strengths and, as expected, carbon fiber composites show up to $63 \%$ higher modulus contents in comparison with glass fiber-reinforced composites. In contrast to a $14 \%$ higher tensile strength of CF (compared to GF), the tensile strength of processed CF composites (compared to GF composites) is on the same level. Aside from an insufficient fiber matrix adhesion, this could be due to a high proportion of very short $C F$ with $L<L_{c r}$ 
which was observed especially in CF-13 and CF-20. The same effect occurs with the flexural modulus and the Charpy impact strength.

The influence of lubricants on mechanical properties is presented in Table 5. The results show that adding $0.5 \%$ wt. of montan waxes, LE or LOP causes a small increase of all mechanical properties, except for unnotched impact strength. This could be attributed to a slightly higher proportion of fibers with $\mathrm{L}>2 \mathrm{~L}_{\text {cr }}$ after injection molding.

A concentration of lubricant LOP higher than $1.0 \%$ wt. especially reduced tensile strength and Charpy impact strength, possibly due to the diminishing adhesion between matrix and fibers. This effect can no longer be compensated by a rising content of fibers with $L>2 L_{c r}$. Thus, the admixture of $2 \%$ wt. of lubricant LOP results in a reduction of tensile strength and in a notched impact strength of $66.8 \%$ and $61.7 \%$, respectively. In Figure 1 the REM micrographs of GF-20, GF-20-LE-2.0 (with $2.0 \%$ of lubricant LE) and GF-20-LOP-2.0 with $2.0 \%$ of lubricant (LOP) are shown. The micrographs of these composites confirm the results of the mechanical testing and indicate that in the two composites with addition of 2.0 $\%$ lubricant, the fiber pull-out is much more pronounced than in the sample GF-20, which is without any addition of lubricant.

Table 5: Selected characteristics of injection molded PA 10.10 with $20 \%$ vol. GF and with lubricants

\begin{tabular}{lccccc}
\hline $\begin{array}{l}\text { Composites } \\
\text { of PA 10.10 }\end{array}$ & $\begin{array}{c}\text { Tensile } \\
\text { modulus } \\
\text { [MPa] }\end{array}$ & $\begin{array}{c}\text { Tensile } \\
\text { strength } \\
{[\mathbf{M P a}]}\end{array}$ & $\begin{array}{c}\text { Elongation } \\
\text { at break } \\
{[\%]}\end{array}$ & $\begin{array}{c}\text { Notched Charpy } \\
\text { impact strength } \\
{\left[\mathbf{k J} / \mathbf{m}^{2}\right]}\end{array}$ & $\begin{array}{c}\text { Unnotched Charpy } \\
\text { impact strength } \\
{\left[\mathbf{k J} / \mathbf{m}^{2}\right]}\end{array}$ \\
\hline GF-20 & $9,295 \pm 70$ & $130.7 \pm 1.0$ & 3.8 & $12.8 \pm 0.5$ & $69.4 \pm 3.3$ \\
GF-20-LE-0.5 & $9,518 \pm 143$ & $133.2 \pm 1.1$ & 3.9 & $13.4 \pm 0.5$ & $61.2 \pm 4.4$ \\
GF-20-LE-1.0 & $9,555 \pm 47$ & $130.0 \pm 1.2$ & 3.0 & $13.3 \pm 0.4$ & $54.4 \pm 1.9$ \\
GF-20-LE-2.0 & $9,401 \pm 51$ & $127.4 \pm 0.5$ & 3.3 & $12.9 \pm 0.3$ & $54.7 \pm 3.8$ \\
GF-20-LOP-0.5 & $9,387 \pm 125$ & $134.5 \pm 1.1$ & 4.0 & $13.8 \pm 0.4$ & $60.5 \pm 2.3$ \\
GF-20-LOP-1.0 & $9,176 \pm 67$ & $125.6 \pm 1.9$ & 3.4 & $11.9 \pm 0.4$ & $53.7 \pm 4.3$ \\
GF-20-LOP-2.0 & $9,009 \pm 101$ & $43.4 \pm 0.3$ & 4.5 & $4.9 \pm 0.2$ & $31.3 \pm 2.3$ \\
\hline
\end{tabular}
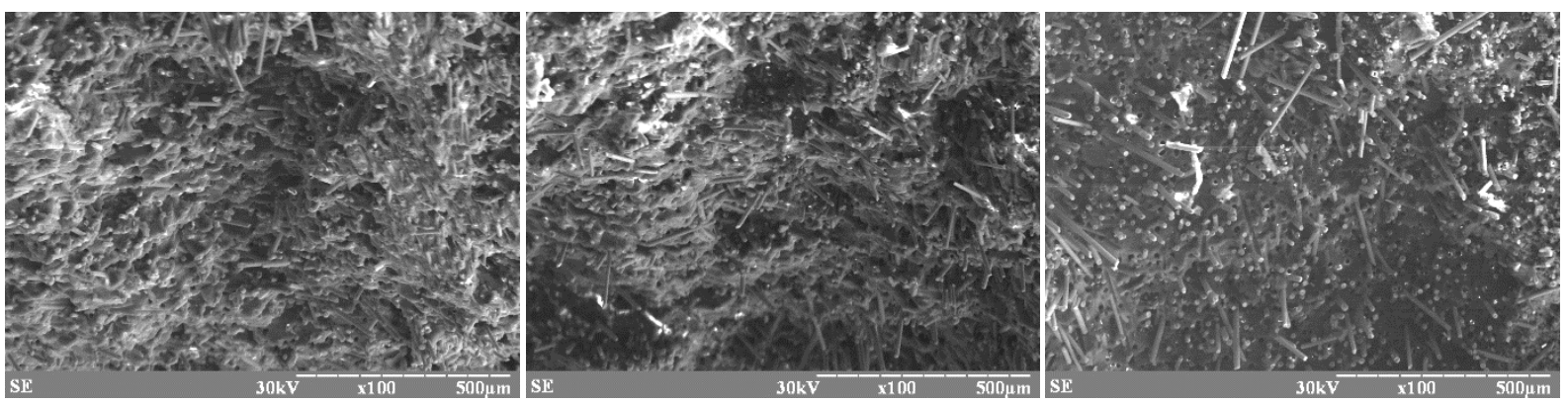

Figure 1: REM micrograph of GF-20 (left), GF-20-LE-2.0 (center) and GF-20-LOP-2.0 (right)

Another approach to optimize composite properties is by varying the processing conditions during injection molding, especially the range of the processing temperature. Figure 2 shows the effect of increasing the processing temperatures on GF composites. The stated temperature ranges represent the temperature settings of the injection molding machine in zone 1 and at the injection nozzle. An efficiency optimum was reached in the temperature range of $275-310^{\circ} \mathrm{C}$ since at higher temperatures the tensile strength of the composites barely increased. A fiber length distribution of $20 \%$ vol. GF for reinforced composites is shown in Table 6 . Considering that the changes in the data of Table 6 are more inconsistent than in Figure 2, it could be assumed that changes in fiber length distribution are not the only reason for higher tensile strength. Increased processing temperatures improve the fiber wetting and increase interfacial adhesion and thus the tensile strength. 


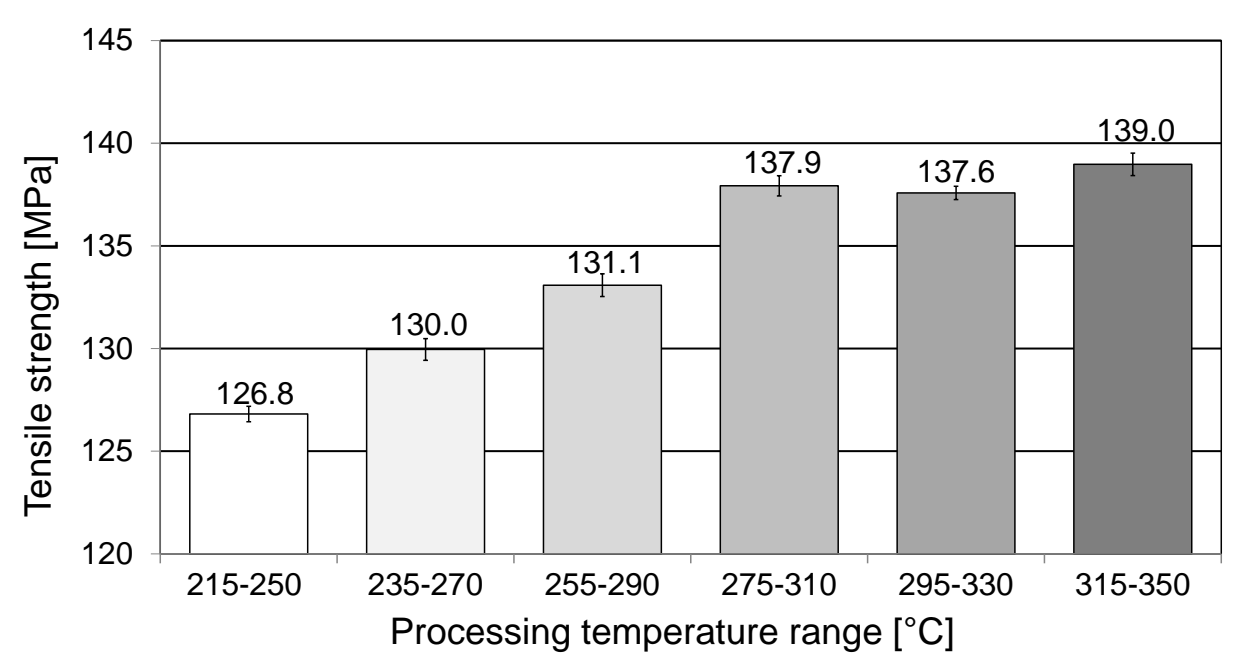

Figure 2: Tensile strength of $20 \%$ vol. glass fiber-reinforced PA 10.10 composites with different injection molding temperature ranges

Table 6: Fiber length distribution in composites of PA 10.10 with $20 \%$ vol. GF

\begin{tabular}{|c|c|c|c|}
\hline \multirow[t]{2}{*}{$\begin{array}{l}\text { Processing } \\
\text { temperature range }\end{array}$} & \multicolumn{3}{|c|}{$\begin{array}{l}\text { Fiber length distribution } \\
\text { after injection molding }\end{array}$} \\
\hline & $\begin{array}{c}\mathrm{L}<\mathrm{L}_{\mathrm{cr}} \\
{[\%]}\end{array}$ & $\begin{array}{c}\mathrm{L}_{c r}<\mathrm{L}<2 \mathrm{~L}_{\mathrm{cr}} \\
{[\%]}\end{array}$ & $\begin{array}{c}2 \mathrm{~L}_{\mathrm{cr}}<\mathrm{L} \\
{[\%]}\end{array}$ \\
\hline 215-250 & 85.7 & 13.7 & 0.6 \\
\hline $235-270$ & 82.4 & 17.0 & 0.6 \\
\hline 255-290 & 84.6 & 14.9 & 0.5 \\
\hline 275-310 & 83.4 & 16.0 & 0.6 \\
\hline 295-330 & 85.1 & 14.6 & 0.3 \\
\hline $315-350$ & 82.1 & 17.3 & 0.6 \\
\hline
\end{tabular}

In lightweight structures, specific properties and temperature resistance are of great importance for the application of plastic compounds and composites. In comparison to GF reinforced composites, CF reinforced composites deliver a specific tensile strength, which is 6-11\% higher, and a specific tensile modulus, which is $63-86 \%$ higher, as shown in Figure 3. For this reason, CF reinforced composites are advantageous in stiffness-dominated structures. In strength-dominated structures, however, GF reinforced composites can be used with almost the same efficiency at significantly lower prizes. For components in the automotive engine compartment, the thermal stability of materials is an outstanding characteristic. In Figure 4, deflection temperatures for unfilled PA10.10 as well as GF and CF reinforced composites are shown under the normal loads of $1.8 \mathrm{MPa}$ (HDT A) and $0.45 \mathrm{MPa}$ (HDT B). It is noticeable that HDT A strongly depends on the fiber volume fraction, which is less pronounced with the HDT B measurements. For respective equal fractions, GF- 6 and CF- 6 show the maximum deviation of $23 \mathrm{~K}, \mathrm{GF}-13$ and CF-13 only show $6 \mathrm{~K}$ which is finally reduced to $3 \mathrm{~K}$ for composites with $20 \%$ vol. fiber content. The HDT B values of the composites, each with the same fiber volume, are within a narrow range. Thus, the composites with $6 \%$ vol. of fibers meet the requirements, e.g. mechanical low-stress housing components in the engine compartment. 


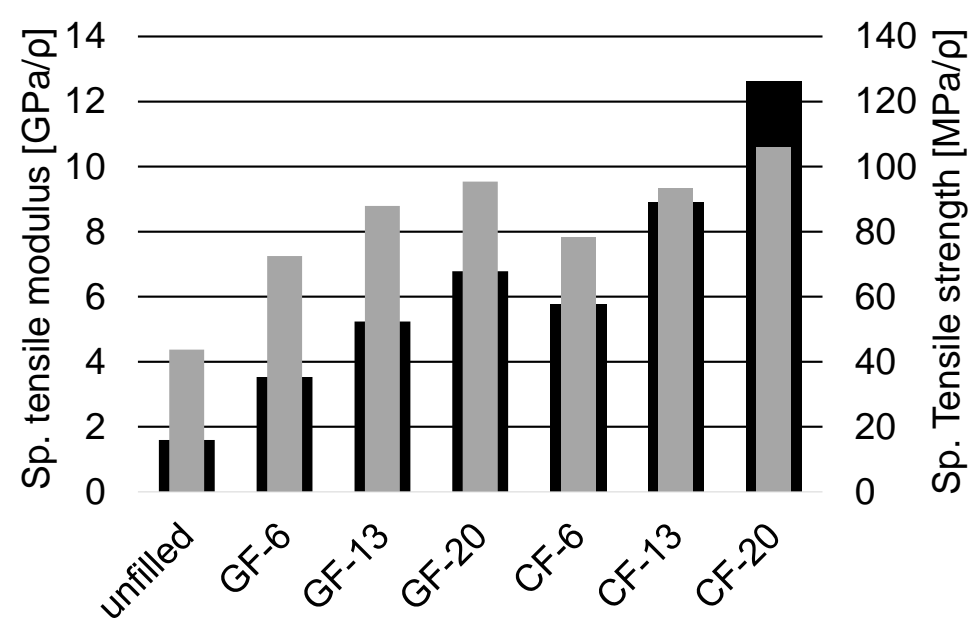

- Specific Tensile modulus - Specific Tensile strength

Figure 3: Specific tensile modulus and strength of PA 10.10 based composites with glass or carbon fibers

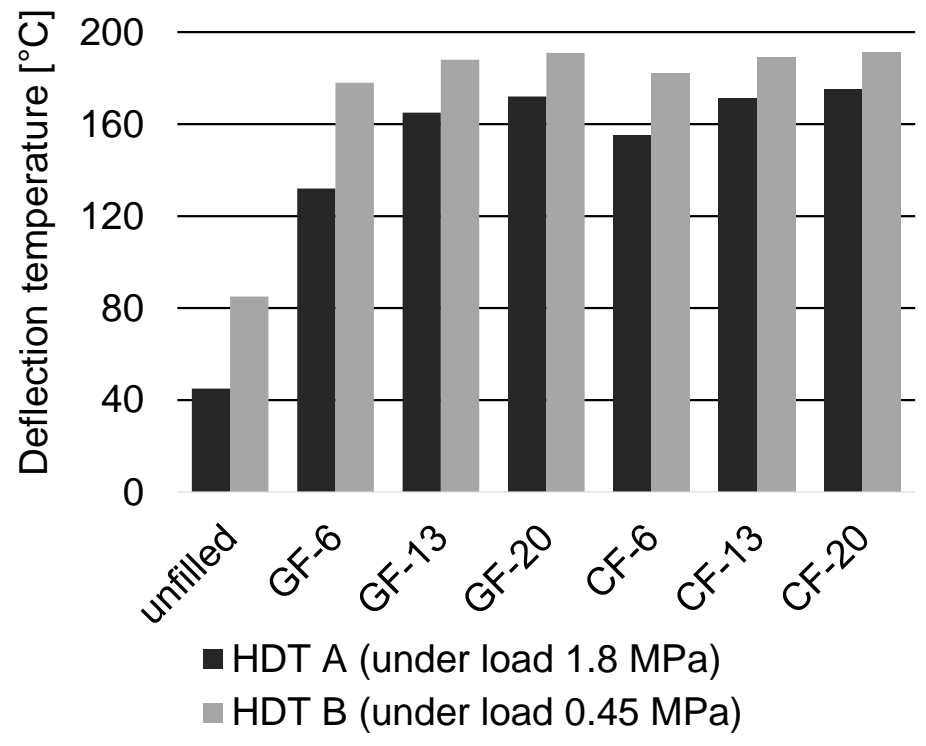

Figure 4: Heat deflection temperatures of PA 10.10 based composites with glass or carbon fibers

\section{Conclusions}

Composites of polyamide 10.10 with proportions of $6 \%, 13 \%$, and $20 \%$ vol. glass and carbon fibers, respectively, were compounded by twin-screw extrusion, processed to test specimens on an injection molding machine and characterized comprehensively. The focus of the investigations was the reinforcing effect of GF and CF and the determination of the effect of fiber breakage on the material properties of the composites. Two processing additives which were derived from montan waxes and prevent fiber breakage during processing were tested. The use of small amounts of these additives resulted in an improvement of the material properties. A dosing of more than $1 \%$ wt., however, worsens the properties and, in particular, the impact strength of the composites. A practicable solution could be the use of an adhesion promoting additive to increase the composite's tensile strength along with a small amount of a fiber sensitive lubricant. Besides that, the processing temperature during injection molding also has a significant influence on the strength of the material. By optimizing the injection molding 
process, an increase in tensile strength of around 9-10\% was achieved. Considering specific moduli of elasticity and tensile strength, the applicability of GF and CF composites with a PA 10.10 matrix in strength- or stiffness-dominated structures is deduced. Analysis of HDT qualifies the composites for use in thermally stressed components e.g. in the engine compartment of vehicles. In order to achieve a high deflection temperature of approx. $180^{\circ} \mathrm{C}$ for mechanically low-stressed components, $6 \%$ GF or CF is sufficient. Regarding our results, this thermal property of the part depends more on the fiber volume content in the composite than on the fiber type.

\section{References}

[1] Bioplastic market data 2016. European Bioplastics e.V., 2016. http://www.european-bioplastics.org/market/ (accessed 20 June 2017).

[2] lavadim, A.; Pilla, S.; Gong, S.; Turng, L.-S.: Biobased and Biodegradable PHBV-Based Polymer Blends and Biocomposites: Properties and Applications. In: Handbook of Bioplastics and Biocomposites Engineering Applications. Hoboken, NJ: Wiley; Salem, Mass: Scrivener, 2011, pp. 372-396.

[3] Thielen, M.: Basics of Bio-polyamides. Bioplastics Magazine, 3 (2010), p. 50.

[4] Thomason, J. L.: Structure-property relationships in glass reinforced polyamide, Part 2: The effects of average fiber diameter and diameter distribution. Polym. Compos. 28(3) (2007), pp. 331-343. doi: 10.1002/pc.20260

[5] Inceoglu, F.; Ville, J.; Ghamri, N; Pradel, J. L.; Durin, A.; Valette R.; Vergnes, B.: Correlation between processing conditions and fiber breakage during compounding of glass fiber-reinforced polyamide. Polym. Compos. 32(11) (2011), pp. 1842-1850. doi: 10.1002/pc.21217

[6] Fu, S. Y.; Mai Y. W.; Lauke, B.: Science and engineering of short fibre reinforced polymer composites. Cambridge: Woodhead Publishing, 2009.

[7] Feldmann, M.; Heim, H. P.; Zarges, J. C.: Influence of the process parameters on the mechanical properties of engineering biocomposites using a twin-screw extruder. Compos. Part A: Appl. Sci. and Manuf., 83 (2016), pp. 113-119. doi: 10.1016/j.compositesa.2015.03.028

[8] Feldmann, M. W.: Biobasierte Polyamide mit Cellulosefasern: Verfahren-Struktur-Eigenschaften. Kassel University Press, 2013.

[9] Feldmann, M.; Bledzki, A. K.: Bio-based polyamides reinforced with cellulosic fibres -processing and properties. Compos. Sci. and Technol., 100 (2014), pp. 113-120. doi: 10.1016/j.compscitech.2014.06.008

[10] Kuciel, S.; Kuźniar, P.; Liber-Kneć, A.: Polyamides from renewable sources as matrices of short fiber reinforced biocomposites. Polimery, 57(9) (2012), pp. 627-634. doi: 10.14314/polimery.2012.627

[11] Kuciel, S.; Kuźnia, P.; Jakubowska, P.: Properties of composites based on polyamide 10.10 reinforced with carbon fiber. Polimery, 61(2) (2016). pp. 106-112. doi: 10.14314/polimery.2016.106

[12] Nikiforov, A. A.; Vol'fson, S. I.; Okhotina, N. A.; Rinberg, R.; Kroll, L.: The influence of processing additives on the properties of glass-fibre-reinforced composites based on biobased polyamide 1010. International Polymer Science and Technology, 44(7) (2017), T43-48.

[13] Nikiforov, A. A.; Vol'fson, S. I.; Okhotina, N. A.; Rinberg, R.; Hartmann, T.; Kroll, L.: Mechanical properties of the compositions based on biopolyamide-1010 modified by carbon, glass, and cellulose chopped fibers. Russ. Metall. (Metally), 2017(4) (2017), pp. 279-282. doi: $10.1134 / \mathrm{S} 0036029517040152$

[14] Nikiforov, A. A.; Okhotina, N. A.; Fayzullin, I. Z.; Volfson, S. I.; Rinberg, R.; Kroll, L.: Stress-strain properties of composites based on bio-based polyamide 1010 filled with cut fibers. AIP Conf. Proc. 1785(1) (2016), pp. 030018-1-030018-4. doi: 10.1063/1.4967039

[15] Nikiforov, A.; Volfson, S.; Rinberg, R.; Hartmann, T.; Kroll L.: New composites from bio-based polyamide with short fibers for lightweight structures. In: Proceedings of 2nd International MERGE Technologies Conference, Chemnitz, Germany, 2015, pp. 109-116.

[16] Mathurosemontri, S.; Uawongsuwan, P.; Nagai, S.; Hamada, H.: The Effect of Processing Parameter on Mechanical Properties of Short Glass Fiber Reinforced Polyoxymethylene 
Composite by Direct Fiber Feeding Injection Molding Process. Energy Procedia, 89 (2016), pp. 255-263. doi: 10.1016/j.egypro.2016.05.033

[17] Lafranche, E.; Krawczak, P.; Ciolczyk, J. P.; Maugey, J.: Injection moulding of long glass fiber reinforced polyamide 66: processing conditions/microstructure/flexural properties relationship. Adv. in Polym. Technol., 24(2) (2005), pp. 114-131. doi: 10.1002/adv.20035

[18] Kerber, M. L.; Golovkin, U. A.; Gorbatkin, U. A. et. al.: Polymernie kompozitcionnie materiali [Polymeric composite materials]. Saint Petersburg: Professia, 2008. 